\title{
Refractory systemic juvenile idiopathic arthritis complicated by coxarthrosis
}

\author{
Antonio Melloš, Angela Mauro, Carmela Granato, Maria Francesca Gicchino, Laura Perrone, Alma Nunzia Olivieri \\ From 21st European Pediatric Rheumatology (PReS) Congress \\ Belgrade, Serbia. 17-21 September 2014
}

\section{Introduction}

S-JIA has the worst long-term prognosis compared to other types of JIA. Corticosteroids, methotrexate and anti - tumor necrosis factor (TNF) are the most commonly used drugs for it. Recently, newer biologic agents targeting IL- 1 and IL- 6 have proven their effectiveness in treating s-JIA and in minimizing corticosteroid exposure.

\section{Objectives}

To describe the challenging management of a case of refractory s-JIA.

\section{Methods}

Laboratory tests and diagnostic imaging were performed taking into account the history and the pathological findings highlighted at the physical examination of a 14 year old girl febrile $\left(38^{\circ} \mathrm{C}\right)$ since about a month, especially in the evening. She appeared pale, suffering from right arthritis of elbow, knee, hip and left arthritis of the ankle and at the third finger of the hand. Diagnosis of s-JIA was made according with ILAR classification criteria (second revision, Edmonton 2001).

\section{Results}

Blood tests found : inflammatory anemia $(\mathrm{Hb} 7.5 \mathrm{~g} / \mathrm{dl}$, ESR $128 \mathrm{~mm} / 1 \mathrm{~h}$, CRP $32 \mathrm{mg} / \mathrm{dl}$, ferritin $485 \mathrm{ng} / \mathrm{dl}$; fibrinogen $634 \mathrm{mg} / \mathrm{dl}$ ); normal WBC count; absence of thrombocytosis; normal PT and aPTT, hypoalbuminemia $(3,1 \mathrm{gr} / \mathrm{dl})$ and an increase of FDP $(>20 \mu \mathrm{g} / \mathrm{l})$ and D-dimer $(8 \mu \mathrm{g} / \mathrm{dl})$. Blood culture and urine test were sterile, ANA and ENA were absent. Eye examination excluded uveitis. Diagnostic imaging didn't found pathological signs. Bone marrow aspiration excluded a primary or metastatic neoplastic disease and hemophagocytosis. Suspecting a s-JIA, we decided to administer intravenous

\footnotetext{
Department of the Women, Child, General and Specialized Surgery, Second
} University of Naples, Italy, Naples, Italy oral administration of prednisone $(1.3 \mathrm{mg} / \mathrm{kg} /$ day $)$, resulting in a marked improvement of the clinical symptoms and blood parameters in seven days. We associated methotrexate (MTX, $10 \mathrm{mg} / \mathrm{m}^{2} /$ week) and naproxen with steroid therapy, we tried several times to climb the steroid dose and reduce it to less than $0.3 \mathrm{mg} / \mathrm{kg}$, but without success. In march 2011, we decided to add anakinra (100 $\mathrm{mg} /$ day subcutaneously) to her therapeutic regimen because of the corticodependence and the poor control of the disease (acute arthrosynovitis of left knee; functional limitation of both hips; Hb 10,5 gr/dl; ESR 35 mm/ 1h; CRP 3,3 mg/dl). After an initial clinical response (absence of acute arthrosynovitis; Hb 11,2 gr/dl; ESR 11 $\mathrm{mm} / 1 \mathrm{~h}$; CRP 0,33 mg/dl), Anakinra has been suspended in july 2011 following the appearance of local reactions at the injection site compromising its administration. It has been replaced with etanercept $(0.4 \mathrm{mg} / \mathrm{kg}$, administered twice per week by subcutaneous injection). In april 2012, because of secondary unilateral coxarthrosis, the patient undergone a cementless total right hip replacement. disease, initially responsive to etanercept ( $\mathrm{Hb} 12,2$ $\mathrm{gr} / \mathrm{dl}$; ESR $18 \mathrm{~mm} / 1 \mathrm{~h}$; CRP 0,12 $\mathrm{mg} / \mathrm{dl}$ ), also became refractory to this biologic drug (arthrosynovitis acute of the right knee and left ankle; functional limitation of both elbows; Hb 10,8mg/dl; ESR 95mm/1h; CRP $11 \mathrm{mg} / \mathrm{dl}$ ). Then, in october 2012 the anti-TNF therapy was discontinued and replaced with canakinumab (150 mg/day subcutaneously), initially effective, but suspended in may 2014 due to the refractory disease. Currently, the patient has acute arthrosynovitis of both knees even though they have already been infiltrated with triamcinolone acetonide, a functional limitation of the left hip and an inflammatory anemia (Hb $10.3 \mathrm{~g} / \mathrm{dl}$; VES 75mm/1h; CRP $8 \mathrm{mg} / \mathrm{dl}$, SAA $99 \mathrm{mg} / \mathrm{L})$. Her current treatment is prednisone $(0.4 \mathrm{mg} / \mathrm{kg} /$ day) associated with indomethacin and MTX. 


\section{Conclusion}

Considering the efficacy of anti-IL-6 blockade described in s-JIA, we're going to start the intravenous infusion of Tocilizumab ( $8 \mathrm{mg} / \mathrm{kg}$ over 60 minutes).

\section{Disclosure of interest}

None declared.

Published: 17 September 2014

doi:10.1186/1546-0096-12-S1-P232

Cite this article as: Mellos et al.: Refractory systemic juvenile idiopathic arthritis complicated by coxarthrosis. Pediatric Rheumatology 201412

(Suppl 1):P232.

Submit your next manuscript to BioMed Central and take full advantage of:

- Convenient online submission

- Thorough peer review

- No space constraints or color figure charges

- Immediate publication on acceptance

- Inclusion in PubMed, CAS, Scopus and Google Scholar

- Research which is freely available for redistribution

Submit your manuscript at www.biomedcentral.com/submit 